\title{
EPIDEMIOLOGY AND PHOSPHOLIPASE ACTIVITY OF ORAL CANDIDA SPP. AMONG PATIENTS WITH CENTRAL NERVOUS SYSTEM DISEASES BEFORE AND AFTER DENTAL CLEANING PROCEDURE
}

\author{
Aurélia Silva Ribeiro ${ }^{1}$, Dágma Aparecida Silva ${ }^{1}$, Francislene Pereira Silva ${ }^{1}$, Gleicy Carla Santos ${ }^{1}$, Lívia Maria Soares \\ Campos $^{1}$, Lorena Vivien Neves Oliveira ${ }^{1}$, Daniel Assis Santos ${ }^{1}$ *
}

${ }^{1}$ Laboratório de Microbiologia, Faculdade de Ciências da Saúde, Universidade Vale do Rio Doce, Governador Valadares, MG, Brasil.

Submitted: September 04, 2008; Returned to authors for corrections: April 09, 2009; Approved: September $28,2009$.

\begin{abstract}
Patients suffering of diseases that affect central nervous system may be considered more susceptible to the infectious diseases of mouth. Sixty-nine patients suffering of cerebral palsy, Down's syndrome and metal retardation were submitted to saliva examination for the presence of Candida spp. before and after a procedure of dental cleaning. The isolates were submitted to assay for verifying phospholipase production. $55.10 \%$ of the patients provided isolation of Candida spp. The frequency of isolation obtained before dental procedure was: C. albicans $(83.33 \%)$, C. krusei (8.33\%) and C. kefyr, C. parapsilosis and C. glabrata (2.78\% each). The frequency after the procedure was: C. albicans (68.57\%), C. parapsilosis (11.43\%), C. krusei and C. kefyr (8.57\% each) and Candida glabrata $(2.86 \%)$. We verified significantly difference (p < 0.01 ) between populations obtained at the two examinations. Phospholipase production was verified only among $C$. albicans strains and the proportion of producers was higher when testing isolates obtained after dental cleaning procedure. Studies focused on Candida spp. isolation are useful for better comprehension of the role of these yeasts on the oral flora from patients with cerebral palsy, Down's syndrome and metal retardation.
\end{abstract}

Key words: Candida spp., cerebral palsy, Down's syndrome, metal retardation, phospholipase.

\section{INTRODUCTION}

Cerebral palsy describes a group of permanent disorders of the development of movement and posture, causing activity limitation that are attributed to nonprogressive disturbances that occurred in the developing fetal or infant brain. The motor disorders of cerebral palsy are often accompanied by disturbances of sensation, perception, cognition, communication, and behaviour, by epilepsy and by secondary musculoskeletal problems (1). Patients suffering of Down's syndrome, Cerebral palsy and/ or Mental Retardation can present mechanical problems in performing oral hygiene, resulting in high proliferation of oral flora (10).

Candida species, mainly C. albicans can live as commensal microorganism in healthy individuals, but it is capable of causing infection if there are predisposing 
conditions related to the host. The infective ability of this yeast also depends on the production of several virulence factors such as germ tube, protease and phospholipase and growth at $37^{\circ} \mathrm{C}(7,9,15,19)$.

Oral colonization with yeast is known to be significantly higher among immunocompromised patients than among healthy people. An increased incidence of asymptomatic oral Candida spp. carriage in HIV positive individuals compared with others at risk groups such as denture wearers has also been noted (3).

Previous studies demonstrated that pathoanatomical disorders predispose children with Down's syndrome to the proliferation of Candida strains, completely populating the floor of the mouth, often causing candidiasis. The onset of the infectious process by Candida in the mouth of children with Down's syndrome, in addition to abnormal innate and acquired immunological conditions, is also influenced by the pathogenic capacity of these yeasts, initially acting as colonizers and later on as infectious agents due to the alteration of the oral flora produced by microbiological, chemical and physical factors, such as chewing and/ or poor mouth cleaning $(14,15)$.

Considering that little is known about Candida spp. on oral flora from patients with Down's syndrome and that studies focused on the isolation of these microorganisms from patients with cerebral palsy and/ or mental retardation are scarce, we aimed to isolate yeasts from the genus Candida from people suffering of these diseases. We also analyzed the phospholipase activity and the influence of dental cleaning procedure on the isolation of the yeasts.

\section{PATIENTS AND METHODS}

\section{Studied population}

Sixty-nine patients with mental retardation (39 individuals), cerebral palsy (19 individuals) and Down's syndrome (11 individuals) aged from 6 to 48 years old, attended by a reference mouth care (Pronto Atendimento Odontológico ao Paciente Especial) from Governador Valadares, Minas Gerais, Brazil, were studied from February to
May of 2008. $60.90 \%$ of the patients were male and $39.10 \%$ were female. This study was approved by the Ethics Committee of the Universidade Vale do Rio Doce (CEP/UNIVALE 012/2008). In all the patients, saliva was collected by swabbing the oral cavity and from the tongue at two different moments: before and immediately after dental cleaning procedure. No antibacterial and/ or antifungal drugs were used in the patients during the cleaning process, which takes around 30 minutes. No patients presented lesions suggesting oral candidosis.

\section{Mycological examination}

Clinical samples were immediately inoculated on Sabouraud-Dextrose Agar (SDA) plates containing chloramphenicol $0.1 \mathrm{~g} / \mathrm{L}$ and were incubated during $48 \mathrm{~h}$ at $28^{\circ} \mathrm{C}$. The yeasts colonies were subcultured on SDA slants were kept at $4^{\circ} \mathrm{C}$ for subsequent identification. The isolates obtained were identified by the germ tube test and by the morphological and biochemical profiles (17).

\section{Phospholipase production}

Candida strains were screened for production of extracellular phospholipase activity by growing them on egg yolk agar and measuring the size of the zone of precipitation by the method of Price et al. (12). Colonies growing for twentyfour hours were subcultured to the egg yolk agar and then incubated at $37^{\circ} \mathrm{C}$ for $48 \mathrm{~h}$. The diameter of the precipitation zone around the colony was determined. Measurement and calculation of the zone of the phospholipase activity $(\mathrm{Pz})$ were calculated as follows: colony diameter/ colony diameter + precipitation zone. $\mathrm{Pz}$ coefficient were classified as negative ( $\mathrm{Pz}=1.00)$, positive $(0.64 \geq \mathrm{Pz}<1.00)$ and strongly positive $(\mathrm{Pz}<0.64)$.

\section{Statistical analysis}

The comparison between obtained results was performed by using the Chi-square test. A p value $<0.01$ was considered to be significant. 


\section{RESULTS AND DISCUSSION}

From all the studied individuals, $38(55.10 \%)$ provided the isolation of Candida spp.. Sex, age and pathological condition did not provided different results between the isolation from patients with one of the three diseases $(\mathrm{p}<0.01)$. This is the first study which involves Candida spp. isolation from patients with cerebral palsy and mental retardation. Some works involving Down's syndrome children were found. Carlsted et al. (2) verified that Candida spp. colonization in patients with Down's syndrome were significantly higher than control individuals. These three groups of patients from our study could be considered more susceptible to mouth infectious diseases, including candidosis, because they may suffer from multiple disorders such as orofacial anomalies, open mouth posture, macroglossia, frequent respiratory diseases, immunological deffects and mouth breathing. The incidence of angular cheilitis (angular stomatitis, perleche and commissural fissures) also appears to be increased (14). According to Vieira et al. (18), Candida spp. from the mouth mucosa from patients with Down's syndrome could take part of dental biofilm in a high proportion, concomitantly with Streptococcus mutans, probably influencing the occurrence of caries, gingivitis and periodontitis.

Table 1 demonstrates the isolation of Candida spp. at the different moments of saliva obtaining. Eighteen patients propitiated $C$. albicans isolation at the two times of examination. Considering isolation before dental procedure, 36 strains were obtained from 34 patients, being $C$. albicans obtained from 30 patients $(83.33 \%)$, followed by C. krusei from 3 (8.33\%), C. kefyr, C. parapsilosis and C. glabrata from 1 patient each (2.78\% each). After dental procedure, Candida isolates were obtained from 32 patients, who provided 35 strains distributed as: C. albicans from 24 patients $(68.57 \%)$, followed C. parapsilosis from 4 patients (11.43\%), C. krusei and C. kefyr from 3 patients each (8.57\%) and Candida glabrata from 1 patient $(2.86 \%)$. We verified significantly difference $(\mathrm{p}<0.01)$ between populations obtained in the two studied moments.

Table 1. Candida spp. isolates obtained from patients with cerebral palsy, Down's syndrome and mental retardation before and after dental cleaning procedure

\begin{tabular}{|c|c|c|}
\hline $\begin{array}{c}\text { Number of } \\
\text { patients }\end{array}$ & $\begin{array}{c}\text { Isolate obtained before dental cleaning } \\
\text { procedure }\end{array}$ & $\begin{array}{c}\text { Isolate obtained after dental cleaning } \\
\text { procedure }\end{array}$ \\
\hline $18(47.37 \%)$ & C. albicans & C. albicans \\
\hline $5(13.16 \%)$ & C. albicans & No isolate \\
\hline $3(7.90 \%)$ & No isolate & C. albicans \\
\hline $1(2.63 \%)$ & C. albicans & C. krusei \\
\hline $1(2.63 \%)$ & C. krusei & No isolate \\
\hline $2(5.27 \%)$ & C. albicans & C. parapsilosis \\
\hline $1(2.63 \%)$ & C. albicans & C. kefyr \\
\hline $1(2.63 \%)$ & C. glabrata & C. glabrata \\
\hline $1(2.63 \%)$ & No isolate & C. parapsilosis \\
\hline $1(2.63 \%)$ & C. albicans and C. krusei & C. krusei \\
\hline $1(2.63 \%)$ & C. krusei & C. krusei and C. kefyr \\
\hline $1(2.63 \%)$ & C. kefyr & C. kefyr and C. albicans \\
\hline $1(2.63 \%)$ & C. albicans and C. parapsilosis & C. albicans and C. parapsilosis \\
\hline $1(2.63 \%)$ & C. albicans & C. albicans and C. parapsilosis \\
\hline
\end{tabular}


The higher prevalence of $C$. albicans attested previous studies focused on the isolation of yeasts from mouth. Furthermore, this species was the most prevalent at the two tested moments, although the frequency was reduced $(\mathrm{p}<0.01)$ from $83.33 \%$ to $68.57 \%$ when comparing isolates obtained before and after dental procedure. In addition, non albicans species (C. parapsilosis, C. krusei and C. kefyr) were more frequently $(\mathrm{p}<0.01)$ after the treatment. C. tropicalis was not isolated from the patients of this study, differing from other researchers that obtained this species as the second most common in oral cavity (13). Erköse and Erturan (3) found that C. albicans was the most frequent isolated from patients infected with human immunodeficiency virus, corresponding to $82.8 \%$ of the studied patients. On the other hand, Resende et al. (13) and Oksuz et al. (11) obtained C. albicans isolation from $62.66 \%$ and $66.4 \%$ of the patients from their works. These data are similar to that found in our work. It is interesting to observe the increasing on the occurrence of $C$. parapsilosis at the second moment of mouth examination. This pathogen has been mentioned as an emergent pathogen and has been isolated in high frequency by other researchers (4).

Two patients provided isolation of two different isolates concomitantly before dental procedure: $C$. albicans and $C$. krusei, which provided only $C$. krusei after the procedure; $C$. albicans and $C$. parapsilosis, which were maintained after dental procedure. Four patients presented two species concomitantly after the procedure, but only one was preceded by the same isolation (this was the patient mentioned above); the other isolations were: $C$. krusei and C. kefyr; C. kefyr and C. albicans; C. albicans and C. parapsilosis (Table 1). All of them were preceded by the isolation of only one strain: $C$. krusei, C. kefyr and C. albicans, respectively. The occurrence of more than one Candida spp. isolate from the same patient was previously demonstrated by Erköse and Erturan (3). It is possible to presume that all these patients were colonized by the two species isolated at both examination times; being the dental procedure responsible for selecting the strain (s) that was more able to adhering to mouth mucosa and it would be isolated. It is also plausible that if only one strain was obtained before dental cleaning and two strains were obtained after that, this procedure could be reducing the population of the species isolated previous (probably the most virulent), propitiating the isolation of two different microorganisms, being the second one possible less virulent.

Six patients presented positive isolation only before the dental cleaning process (from whom 5 were $C$. albicans) and four isolation only after the procedure (from whom 3 were $C$. albicans). From our point of view, the isolation of C. albicans only after dental procedure could be attributed to a possible competition between yeasts and bacteria at the moment of the saliva obtaining. It may well yield the result that the microbiological examination tends to isolate the strain that would be pathogenically predominant at the time.

The phospholipase production was verified to be positive only among $C$. albicans isolates, being the other species negative for its production. $15(50.00 \%)$ and 14 (58.33\%) C. albicans were phospholipase producers before and after dental procedure, respectively. These results are similar to that found by Gokce et al. (5), who verified phospholipase production only in $C$. albicans. When studying the phospholipase production from Candida spp. isolated from anatomically distinct sites of healthy adults, Oksuz et al. (11) verified that the activity of exoenzyme was higher in oral isolates. The presumed mechanism for all invasive $C$. albicans disease involves initial mucosal surface colonization followed by invasion into the adjacent tissues and organs. The ability of $C$. albicans to produce secretory enzymes such as phospholipase may play an important role in the pathogenicity of these yeasts (10, 15, 16, 19). According to Ibrahim et al. (6), extracellular phospholipases facilitate the ability of these organisms to injure, invade, egress form various host cells and/or remove processed antigens from the surface of antigen-presenting cells. We verified an increasing of phospholipase production from isolates obtained after dental procedure. Probably it may act as an advantage factor for the colonization and persistence of the yeasts in oral mucosa. Furthermore, commensal organisms such as $C$. albicans are able to persistently colonize the host without causing symptoms. However, the balance between 
commensalism and pathogenicity is delicate (8). How these two states are modulated during colonization is a major area of research in medical mycology, with the aim of utilizing the knowledge gained for the benefit of the patient (19). Considering that patients from our study may be more susceptible for mouth infectious diseases, further studies are necessary to clarify whether Candida spp. population in oral mucosa could constitute a risk factor for candidosis and whether dental cleaning procedure could be a preventive action for that diseases.

\section{ACKNOWLEDGEMENTS}

This work was supported by Fundação de Amparo a Pesquisa do Estado de Minas Gerais (FAPEMIG) grant CBB APQ-2864-4.01/07.

\section{REFERENCES}

1. Anttila, H.; Suoranta, J.; Malmivaara, A.; Mäkelä, M.; Autti-Rämö, I. (2008). Effectiveness of physiotherapy and conductive education interventions in children with cerebral palsy: a focused review. Am J Phys Med Rehabil. 87, 478-501.

2. Carlstedt, K.; Krekmanova, L.; Dahllöf, G.; Ericsson, B.; Braathen, G.; Modéer, T. (1996). Oral carriage of Candida species in children and adolescents with Down's syndrome. Int J Paediatr Dent. 6, 95-100.

3. Erköse, G.; Erturan, Z. (2007). Oral Candida colonization of human immunodeficiency virus infected subjects in Turkey and its relation with viral load and CD4+ T-lymphocyte count. Mycoses. 50, 485-490.

4. Figueiredo, V.T.; Santos, D.A.; Resende, M.A.; Hamdan, J.S. (2007). Identification and in vitro susceptibility of 200 clinical isolates of Candida spp. responsible for fingernail onychomycosis. Mycopatholgia. 164, 27-33.

5. Gokce, G.; Cerikcioglu, N.; Yagci, A. (2007). Acid proteinase, phospholipase, and biofilm production of Candida species isolated from blood cultures. Mycopathologia. 164, 265-269.

6. Ibrahim, A.S.; Mirbod, F.; Filler, S.G.; Banno, Y.; Cole, G.T.; Kitajima, Y.; Edwards, J.E.; Nozawa, Y.; Ghannoum, M.A. (1995). Evidence implicating phospholipase as a virulence factor of Candida albicans. Infection and Immunity. 63, 1993-1998.

7. Koga-Ito, C.Y.; Lyon, J.P.; Vidotto, V.; de Resende, M.A. (2006). Virulence factors and antifungal susceptibility of Candida albicans isolates from oral candidosis patients and control individuals. Mycopathologia. 161, 219-223.

8. Koh, A.Y.; Köhler, J.R.; Coggshall, K.T.; Van Rooijen, N.; Pier, G.B. (2008). Mucosal damage and neutropenia are required for Candida albicans dissemination. PLoS Pathog. 8 (2), e35.

9. Krauke, Y.; Sychrova, H. (2008). Functional comparison of plasmamembrane $\mathrm{Na}+\mathrm{H}+$ antiporters from two pathogenic Candida species. BMC Microbiol. 8 (80), 1-9.

10. Linossier, A.; Vargas, A.; Villegas, R.; Chimenos, E. (2002). Quantitative relationship between salivary level of Streptococcus mutans and Candida albicans in children with Down's syndrome. Med Oral. 7, 284-292.

11. Oksuz, S.; Sahin, I.; Yildirim, M.; Gulcan, A.; Yavuz, T.; Kaya, D.; Koc, A.N. (2007). Phospholipase and proteinase activities in different Candida species isolated from anatomically distinct sites of healthy adults. Jpn $J$ Infect Dis. 60, 280-283.

12. Price, M.F.; Cawson, R.A. (1977). Phospholipase activity in Candida albicans. Sabouraudia. 15, $179-189$.

13. 13. Resende, M.A.; Sousa, L.V.; Oliveira, R.C.; Koga-Ito, C.Y.; Lyon, J.P. (2006). Prevalence and antifungal susceptibility of yeasts obtained from the oral cavity of elderly individuals. Mycopathologia. 162, 39-44.

14. Ribeiro, E.L.; Scroferneker, M.L.; Cavalhaes, M.S.; Campos, C.C.; Nagato, G.M.; Souza, N.A.; Ferreira, W.M.; Cardoso, C.G.; Dias, S.M.; Pimenta, F.C.; Toledo, O.A. (2006). Phenotypic aspects of oral strains of Candida albicans in children with Down's syndrome. Braz J Biol. 66, 939-944.

15. Ribeiro, E.L.; Campos, C.; Crespo, M.; Castro, J.S.; Rocha, F.P.; Alves, M.; Goulart, M.S.; Cardoso, C.; Ferreira, W.; Naves, P.L.; Soares, A.J.; Miranda, S.R.; Pimenta, F.C. (2002). Detection of phospholipidolytic Candida albicans isolated from saliva of children with Down's syndrome. Acta Med Port. 15, 171-174.

16. Rupp, S. (2007). Interactions of the fungal pathogen Candida albicans with the host. Future Microbiol. 2, 141-151.

17. Van Der Walt, J.P.; Yarrow, D. (1984). Methods for the isolation, maintenance, classification and identification of yeasts. In: Kreger-van Rij NJW, editor. The Yeasts. Elsevier Publishers, Amsterdan p. 45-104.

18. Vieira, J.D.; Ribeiro, E.L.; Campos, C.C.; Pimenta, F.C.; Toledo, O.A.; Nagato, G.M.; Souza, N.A.; Ferreira, W.M.; Cardoso, C.G.; Dias, S.M.; Araújo Júnior, C.A.; Zatta, D.T.; Santos, J.S. (2005). Candida albicans isolated from buccal cavity of children with Down's syndrome: occurrence and growth inhibition by Streptomyces sp. Rev Soc Bras Med Trop. 38, 383-386.

19. White, S.J.; Rosenbach, A.; Lephart, P.; Nguyen, D.; Benjamin, A.; Tzipori, S.; Whiteway, M.; Mecsas, J.; Kumamoto, C.A. (2007). Selfregulation of Candida albicans population size during GI colonization.PLoS Pathog. 3 (12), e184. 